\title{
JURISPRUDENCIA AMBIENTAL EN LA COMUNIDAD VALENCIANA (SEGUNDO SEMESTRE 2017)
}

\section{JURISPRUDĖNCIA AMBIENTAL A LA COMUNITAT VALENCIANA (SEGON SEMESTRE 2017)}

\author{
MARTA OLLER RUBERT \\ Professora contractada doctora de Dret Administratiu \\ Universitat Jaume I
}


Sumario: 1. Contaminación acústica: STSJCV 5567/2017, de 14 de julio. 2.Principio "quien contamina, paga": Sentencia del Tribunal Superior de Justicia de la Comunidad Valenciana 1506/2017, 4 de abril. 3.Protección paisajística de suelo no urbano: Sentencia del Tribunal Superior de Justicia de la Comunidad Valenciana 4288/2017, de 9 de junio.

\section{Contaminación acústica: Sentencia del Tribunal Superior de Justicia de la Comunidad Valenciana 5567/2017, de 14 de julio.}

El asunto clave a tratar en este pronunciamiento es la reclamación realizada por un vecino frente al ruido realizado en una zona declarada "zona acústicamente saturada" (en adelante ZAS).

En esta sentencia el TSJ de la Comunidad Valenciana resuelve un recurso de apelación presentado por una ciudadana frente a la Sentencia del Juzgado de lo Contencioso-Administrativo número 1 de Castellón de fecha 27 de mayo de 2.014 que declara inadmisible el recurso contencioso-administrativo interpuesto por la misma, alegando como causa la falta de legitimación, ya que considera el Juzgado de instancia que la recurrente al no vivir en la zona acústica saturada, no tiene un interés directo, y además no forma parte tampoco de la asociación encargada de la tutela medioambiental, en los términos de la Ley 27/2006, de 18 de julio. Al hilo de esta causa de inadmisión se plantea la cuestión de si existe en materia ambiental una acción pública, similar a otros ámbitos, como el urbanístico, que permita a cualquier persona exigir el cumplimiento de la legalidad. Al respecto, efectivamente la jurisprudencia señala que no existe dicha acción pública ambiental, pero que sí que debe interpretarse el requisito de legitimidad cuando se pretende la protección del medio ambiente, de manera flexible y amplia, como en su día señaló el Tribunal Supremo en la sentencia de fecha 22 de abril de 2.002, recurso 3799/1997. En este caso, aunque nos e resida en la calle afectada por la zona ZAS, al ser el recurrente propietario de una vivienda se considera que si bien no un interés directo, sí existe un interés legítimo que le otorga legitimidad para interponer el recurso.

Sin embargo, el fondo de la cuestión abordado en este litigio se refiere al derecho a obtener una protección por parte de los poderes públicos contra el ruido, por parte de la apelante. Para ello el TSJCV alude a jurisprudencia tanto europea - Tribunal 
Europeo de Derechos Humanos de 16.11.2004 y de 19.2.1998, caso Guerra contra Italia-, como nacional - Tribunal Constitucional de fecha 23.2.2004- y pasa a examinar seguidamente la pretensión de la apelante que es la adopción de las medidas correctoras más eficaces que las existentes tras la declaración de la ZAS para la reducción de los niveles sonoros, y entre ellas la reducción del horario de apertura. Al respecto, y en vista de los informes periciales, el TSJCV considera que no procede estimar la reducción de horarios, pero sí que se conmina al Ayuntamiento de Benicassim a que disponga de las medidas necesarias para que se cumpla con medidas correctoras más eficaces respecto de la ZAS, puesto que "las Corporaciones locales y demás Administraciones Públicas no son solamente creadoras de normas, sino también destinatarias del cumplimiento de las mismas. En consecuencia, no es posible la dispensa ni la suspensión de la aplicación ni la tolerancia en el incumplimiento respecto de la aplicación de la normativa local en materia de ruido".

La segunda pretensión de la actora se refiere al ejercicio del derecho de acceso a la información ambiental, regulada por la Ley 27/2006. Insiste acertadamente el tribunal en que este derecho debe interpretarse de manera amplia, de forma que en el caso que nos afecta procede el acceso a la información solicitada.

\section{Principio "quien contamina, paga": Sentencia del Tribunal Superior de Justicia de la Comunidad Valenciana 1506/2017, 4 de abril.}

En esta sentencia se realiza un planteamiento que llama la atención del principio ambiental "quien contamina, paga". En efecto, en el litigo se plantea el recurso por parte de un ciudadano contra un reglamento, la Ordenanza reguladora de la Tasa por prestación de servicios para la protección de la contaminación acústica en el municipio de Elche, alegándose que la misma -y en concreto su artículo 3.1.a)- era contrario tanto al Derecho europeo como al espíritu y finalidad de la Ley 37/2003, de 17 de noviembre, del Ruido, y de su Disposición adicional sexta, pues aquel precepto establecía la imposición de un tasa al denunciante de contaminación 
acústica. Como destaca el Tribunal ello supone ir en contra del espíritu del principio "quien contamina, paga" y del principio de prevención propios del Derecho ambiental, de tal manera que los costes que de dichas denuncias se deriven habrán de ser asumidos por los titulares de las actividades efectivamente contaminantes, y no por quien interponga la denuncia e inste la inspección, por ello el Tribunal Superior de Justicia de la Comunidad Valenciana estima el recurso presentado y declara nulo el art.3.1.a) de la citada Ordenanza.

\section{Protección paisajística de suelo no urbano: Sentencia del Tribunal Superior de Justicia de la Comunidad Valenciana 4288/2017, de 9 de junio.}

En este caso se recurre en apelación una sentencia en el que se desestimaba el recurso contra el Acuerdo del Ayuntamiento de Peñíscola en el que se deniega una licencia para la realización de obras rehabilitación y ampliación de almacén de aperos, a pesar de contar con informes municipales favorables; informes que , como señala el TSJCV, solo indican que las obras eran legales, pero que dada la especial ubicación de los terrenos del demandante dentro el área de protección paisajística de la zona de protección que aprobó definitivamente el PORN, están clasificados a efectos urbanísticos como suelo no urbanizable de protección especial. Esto último, limita el tipo de obras que pueden realizarse, en concreto solo son posibles aquellas obras que respondan a necesidades de tipo agrícola, y, en este caso, claramente se constante que las necesidades y finalidades de las obras que se pretenden son totalmente contrapuestas al tratarse de una edificación de aspecto residencial. Por ello, los preceptivos informes vinculantes emitidos por los órganos autonómicos son desfavorables y en consecuencia el TSJCV desestima el recurso de apelación. 
Sumari: 1. Contaminació acústica: STSJCV 5567/2017, de 14 de juliol. 2. Principi "qui contamina, paga": Sentència del Tribunal Superior de Justícia de la Comunitat Valenciana 1506/2017, 4 d'abril. 3. Protecció paisatgística de sòl no urbà: Sentència del Tribunal Superior de Justícia de la Comunitat Valenciana 4288/2017, de 9 de juny.

\section{Contaminació acústica: Sentència del Tribunal Superior de Justícia de la} Comunitat Valenciana 5567/2017, de 14 de juliol

L'assumpte clau que tracta aquest pronunciament és la reclamació feta per un veí davant del soroll ocasionat en una zona declarada "zona acústicament saturada" (d'ara endavant ZAS).

En aquesta sentència el TSJ de la Comunitat Valenciana resol un recurs d'apel-lació presentat per una ciutadana enfront de la Sentència del Jutjat Contenciós Administratiu número 1 de Castelló de data 27 de maig de 2014, que declara inadmissible el recurs contenciós administratiu interposat per la mateixa ciutadana, al-legant com a causa la falta de legitimació, ja que el Jutjat d'Instància considera que la part recurrent, com que no viu a la zona acústica saturada, no té un interès directe, i a més tampoc no forma part de l'associació encarregada de la tutela mediambiental, en els termes de la Llei 27/2006, de 18 de juliol. Al fil d'aquesta causa d'inadmissió es planteja la qüestió de si existeix en matèria ambiental una acció pública, similar a altres àmbits, com l'urbanístic, que permeti a qualsevol persona exigir el compliment de la legalitat. Sobre aquest tema, efectivament la jurisprudència assenyala que no existeix aquesta acció pública ambiental, però que sí que ha d'interpretar-se el requisit de legitimitat quan es pretén la protecció del medi ambient, de manera flexible i àmplia, com en el moment oportú va assenyalar el Tribunal Suprem en la Sentència de data 22 d'abril de 2002, Recurs 3799/1997. En aquest cas, encara que no resideixi al carrer afectat per la zona ZAS, com que la part recurrent és propietària d'un habitatge, es considera que si bé no és un interès directe, sí que existeix un interès legítim que li atorga legitimitat per interposar el recurs.

No obstant això, el fons de la qüestió que aborda aquest litigi fa referència al dret a obtenir protecció per part dels poders públics contra el soroll, per part de l'apel-lant. 
Per això, el TSJCV al-ludeix a jurisprudència tant europea - Tribunal Europeu de Drets Humans de 16.11.2004 i de 19.2.1998, cas Guerra contra Itàlia-, com nacional - Tribunal Constitucional de data 23.2.2004- i seguidament passa a examinar la pretensió de la part apel-lant, que és l'adopció de les mesures correctores més eficaces que les existents després de la declaració de la ZAS per a la reducció dels nivells sonors, i entre les quals la reducció de l'horari d'obertura. Sobre aquest tema, i en vista dels informes pericials, el TSJCV considera que no procedeix estimar la reducció d'horaris, però sí que es commina a l'Ajuntament de Benicàssim que disposi de les mesures necessàries perquè es compleixi amb mesures correctores més eficaces respecte de la ZAS, ja que "les corporacions locals i altres administracions públiques no són solament creadores de normes, sinó també destinatàries del seu compliment. En conseqüència, no és possible la dispensa ni la suspensió de l'aplicació ni la tolerància en l'incompliment respecte de l'aplicació de la normativa local en matèria de soroll".

La segona pretensió de l'actora fa referència a l'exercici del dret d'accés a la informació ambiental, regulada per la Llei 27/2006. El Tribunal insisteix encertadament que aquest dret ha d'interpretar-se àmpliament, de manera que en el cas que ens afecta procedeix l'accés a la informació sol-licitada.

\section{Principi "qui contamina, paga": Sentència del Tribunal Superior de Justícia de la Comunitat Valenciana 1506/2017, 4 d'abril}

En aquesta sentència té lloc un plantejament que crida l'atenció del principi ambiental "qui contamina, paga". En efecte, en el litigi es planteja el recurs per part d'un ciutadà contra un reglament, l'Ordenança reguladora de la taxa per prestació de serveis per a la protecció de la contaminació acústica al municipi d'Elx, i s'al-lega que la mateixa -i en concret l'article 3.1.a) - era contrari tant al Dret europeu com a l'esperit i la finalitat de la Llei 37/2003, de 17 de novembre, del soroll, i de la seva disposició addicional sisena, ja que aquell precepte establia la imposició d'un taxa a la part denunciant de contaminació acústica. Com destaca el Tribunal, això suposa anar en contra de l'esperit del principi "qui contamina, paga" i del principi de 
prevenció propis del dret ambiental, de manera que els costos que es derivin d'aquestes denúncies han de ser assumits pels titulars de les activitats efectivament contaminants, i no per qui interposi la denúncia i insti la inspecció, per això el Tribunal Superior de Justícia de la Comunitat Valenciana estima el recurs presentat i declara nul l'article 3.1.a) de l'esmentada ordenança.

\section{Protecció paisatgística de sòl no urbà: Sentència del Tribunal Superior de Justícia de la Comunitat Valenciana 4288/2017, de 9 de juny}

En aquest cas es recorre en apel-lació una sentència en què es desestimava el recurs contra l'Acord de l'Ajuntament de Peníscola en què es denega una llicència per dur a terme obres de rehabilitació i ampliació de magatzem d'eines, malgrat disposar d'informes municipals favorables; informes que, com assenyala el TSJCV, solament indiquen que les obres eren legals, però que atesa l'especial ubicació dels terrenys de la part demandant dins l'àrea de protecció paisatgística de la zona de protecció que va aprovar definitivament el PORN, es classifiquen a efectes urbanístics com a sòl no urbanitzable de protecció especial. Això últim, limita el tipus d'obres que es poden dur a terme, en concret només són possibles les obres que responguin a necessitats de tipus agrícola, i, en aquest cas, clarament es constati que les necessitats i finalitats de les obres que es pretenen són totalment contraposades, ja que es tracta d'una edificació d'aspecte residencial. Per això, els preceptius informes vinculants emesos pels òrgans autonòmics són desfavorables i, en conseqüència, el TSJCV desestima el recurs d'apel·lació. 